\title{
Analysis of Energy Consumption Using Sequential to Better Signal (SBS) Scheme for Green Cellular Network
}

\author{
Haniah Mahmudah, Okkie Puspitorini, Ari Wijayanti, \\ Nur Adi Siswandari, Yetik Dwi Kusumaningrum \\ Telecommunication Engineering \\ Politeknik Elektronika Negeri Surabaya \\ Jalan Raya ITS, Sukolilo 60111, Indonesia \\ E-mail: haniah@pens.ac.id
}

Received February 4, 2020; Revised March 2, 2020; Accepted May 25, 2020

\begin{abstract}
Over time, cellular communication technology developed significantly from year to year. This is due to increasing the number of users and the higher needed. To overcome this problem, many providers increase the number of new base station installations to fill up the customer's needed. The increase number of base stations does not take into account the amount of power consumption produced, where in the cellular network Base Stations (BS) are the most dominant energy consuming equipment estimated at $60 \%-80 \%$ of the total energy consumption in the cellular industry. In addition, energy waste often occurs in the BS where the emission power will always remain even if the number of users is small. Power consumption and energy savings are important issues at this time because they will affect $\mathrm{CO} 2$ emissions in the air. This paper proposes to save energy consumption from BS by turning off BS (sleep mode) if the number of users is small and distributed to other BS (neighboring BS) which is called cell zooming technique. The cell size can zoom out when the load traffic is high and zoom in when the load traffic is low. To determine the central BS and neighboring BS, a sequential to better signal (SBS) scheme is used where this scheme sorts neighboring $\mathrm{BS}$ based on the SINR value received (user). The results of this research, base station can be able to save energy $29.12 \%$ and reduce $\mathrm{CO} 2$ emission around $3580 \mathrm{~kg} /$ year. It means saving energy consumption which is also reducing air pollution occurs and this term can be named as green cellular network.
\end{abstract}

Keywords: Energy Consumption, SINR, Sequential to Better Signal (SBS), Green Cellular Network. 


\section{INTRODUCTION}

Nowadays, the evolution of mobile devices and communication technology (ICT) have fantastic growth which is caused by increasing the number of mobile users and broadband service. The higher number of customers and services provided, providers must also try to provide good service (QoS). To be able to serve such a big amount of traffic, mobile networks have 2 ways to overcome this problem, first is increase their capacity and second increase the number of BS installation. Generally, the second ways are being used by providers. In wireless network, base stations consume about two-third of total network power consumption and are logically responsible for $70 \%$ of $\mathrm{CO} 2$ emission from entire network [1,2] High electricity payments are due to power consumption from the BS, which is power amplifiers dominate the energy consumption of BS where energy efficiency depends on the frequency band, modulation, and operating environment [3].

Reducing energy consumption is a major problem for industry, because it is economic, environmental and marketing reasons. Because the energy consumption of a BS mainly comes from baseband signal processor, controller, air-conditioner and etc., rather than transmit power which consumes only $3.1 \%$ [4], turning BSs into sleep mode whenever possible is considered as a promising technique to reduce the energy consumption.

Cell zooming technique is one of the proposed ways that can be used as a step to save energy on the multicell site where changes in coverage area (coverage) are adjusted to the traffic load at that time, so that in this state the cell can be said to breathe (cell breathing) because can enlarge and reduce the coverage area. When traffic is high, the cell will expand (zoom out), and vice versa when traffic is low, the cell will narrow (zoom in), as shown on Figure 1.

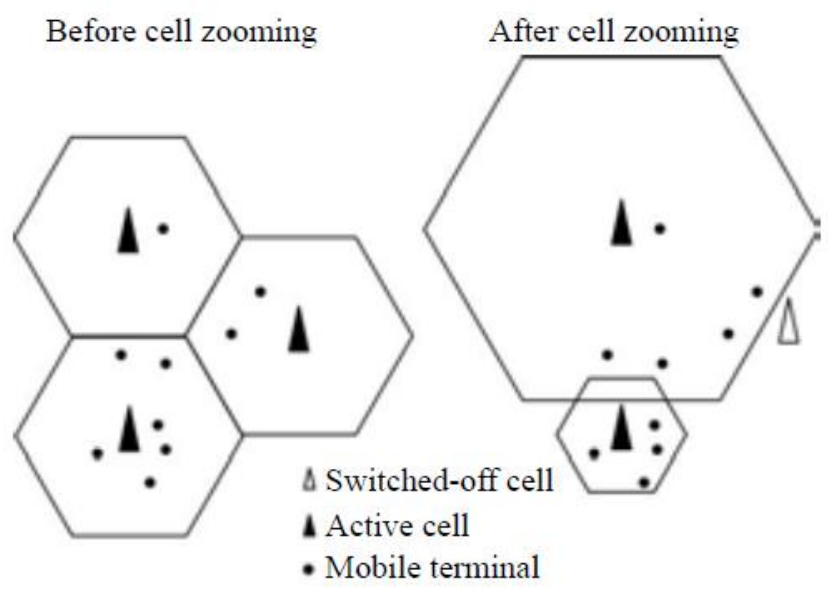

Figure 1. Conceptual scheme of cell zooming [5] 
Cell zooming is about traffic load balancing and reducing the energy consumption. During high traffic period, there can be a scenario where a base station is over loaded whereas the adjacent ones are lightly loaded. The concept of load balancing finds its application here. The technique of transferring the load from heavily loaded base station to the lightly loaded one is termed as load balancing. Cell zooming is commonly termed as the adaptive adjustment of the transmission power according to the traffic load. In practice cell zooming is made possible by usage of a cell zooming server. It is the server attached with the base stations take decision whether to zoom in or zoom out or go for sleep analyzing the traffic density [6].

Using the SBS (Sequential to Better Signal) scheme that is applied to the cell zooming concept, the central BS is switched off to sleep mode and the user equipment (EU) in the central BS is distributed to the neighboring BS. The neighboring Base Station will be sorted according to the Signal to Interference plus Noise Ratio descending value.

\section{RELATED WORKS}

BS sleeping is drawing more and more attention in recent years. Researches started working over the concept of green cellular networks after realizing the desperate need for energy conservation.

Zhiseng Niu, Zexi Tsinghua, Yiqun $\mathrm{Wu}$, Jie Gong [6] have conducted research on "Cell Zooming for Cost-Efficient Green Cellular Networks" by using two algorithms namely centralized and distributed. The result is that centralized algorithms can achieve trade-offs better than distributed algorithms and centralized algorithms can achieve better performance compared to 3 static algorithms and centralized and more flexible centralized algorithms and freer use of trade-offs between normalized energy consumption and outage probability.

Md. Farhad Hossain [7] discussed "Traffic-Driven Energy Efficient Operational Mechanisms in Cellular Access Networks". In this paper, there are several discussion sub-chapters such as the Energy Efficient Cellular Network, Distributed Dynamic Switching of Base Station, and Joint Dynamic Sectorization and Base Station Switching. One of them is to discuss the UE Association Provisions. The provisions of the EU association in this study are based on neighboring BS $B_{i, n}=\left\{B_{n i, 1,1}, B_{n i, 2}, B_{n i}, N_{i, b}\right\}$ which are active from Bi based The closest neighboring BS to combine an UE is located at Bi. By listing only neighbors that are active on Bi,n, the BS in sleep mode allows sleep for a longer time and the number of switching is reduced. Various strategies for sorting new BS neighbors are discussed in this sub-chapter. There are 4 combinations that have been observed, including: Lower-toHigher (LH), Higher-to-Lower (HL), Sequential-to-Sequential (SS), and Sequential-to-Better Signal (SBS).

Haniah [8] discussed "Performance Analysis of Cell Zooming Based Centralized Algorithm for Energy Efficient in Surabaya". In this paper, 
proposed cell zooming technique which can adjusts the cell size dynamic based on traffic condition. The simulation result by using 2 scenarios Lowerto-Higher (LH) scheme and Higher-to-Lower (HL). From both of these schemes, this paper analyzes that by using Lower-to-Higher (LH) scheme reduces energy consumption greater than using Higher-to-Lower (HL) scheme. By using Lower-to-Higher (LH) scheme can save the network energy consumption up to 70,79\%, and by using higher-to-lower (HL) scheme can save the network energy consumption up to $32,33 \%$.

According to reference [6] this research only investigates traffic load from BS and then it is sorted. The other research, energy efficient cellular network, distributed dynamic switching of BS, and Joint dynamic sectorization and BS switching. One of them is to discuss the UE Association Provisions using switching [7]. In addition, reference [8] stated that energy efficiency was taken from receiver power. While in this study the discussion and attention power signal can be affected by power comparison and noise SINR that is Sequential to Better Signal (SBS) scheme.

\section{ORIGINALITY}

Advances in ICT technology have led to an increase in energy consumption of BS which mean requirement of higher energy efficiency is needed. There are some techniques to enable an energy efficient or green cellular network utilizing cell zooming operations as seen on Figure 2. SBS scheme is one of the methods for reduce the energy consumption in cellular network. This paper proposes new approaches for energy efficient method based on actual condition as follows : (1) Traffic data UMTS-based cellular access networks using Macrocell base stations deployment (2) Central business district (CBD) area for deployment scenario in Surabaya, (3) Using the SBS scheme where neighboring BS is set and sorted according to the descending sequence from SINR (Signal to Interference plus Noise Ratio) received and no re-sorting is carried out on the BS (4). Calculation energy consumption per year is performed and then (5) CO2 emission using conversion factor Green House Gas (GHG) emissions is calculated.

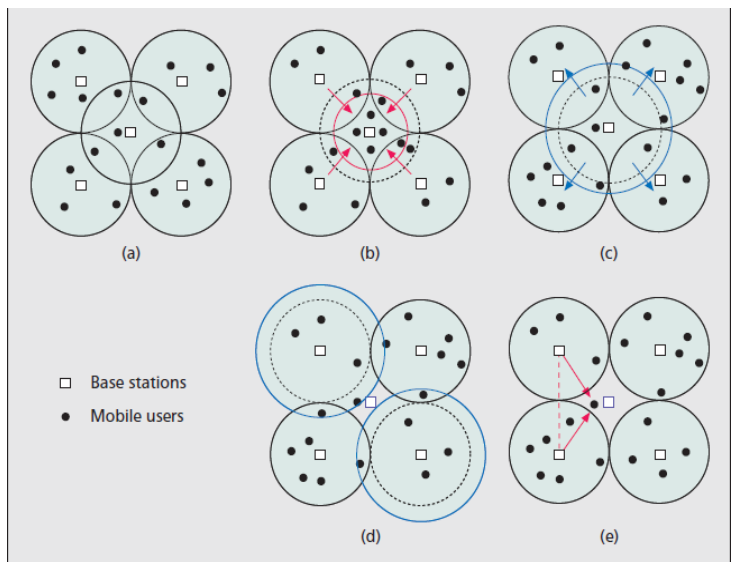

Figure 2. Cell zooming operations in cellular networks 
The SBS scheme can be applied to heavy traffic because SBS is able to connect user equipment (EU) to BS in accordance with the higher SINR. The SBS scheme will be used to sort neighboring BS based on the provisions of the EU association (User Equipment) with only BS neighbors active in $\mathrm{Bi}, \mathrm{n}$. The $\mathrm{BS}$ in sleep mode allows sleep for a longer time and the number of switching is reduced. There are several ways to sort the neighboring active BS, one of them is the SBS scheme where $\mathrm{Bn}$ is a neighboring BS is set and sorted according to the descending sequence from SINR (Signal to Interference plus Noise Ratio) received. As a result of this research, net energy consumption BS of each periods of time are calculated and are being analyzed. Finally, $\mathrm{CO} 2$ emission is calculated based on conversion factor Green House Gas (GHG) emissions.

\section{SYSTEM DESIGN}

In this section will be explained about the application design from work starting from the input, process, and output stages to get the final goal of this research. The whole system design of this simulation is illustrated in Figure 3.

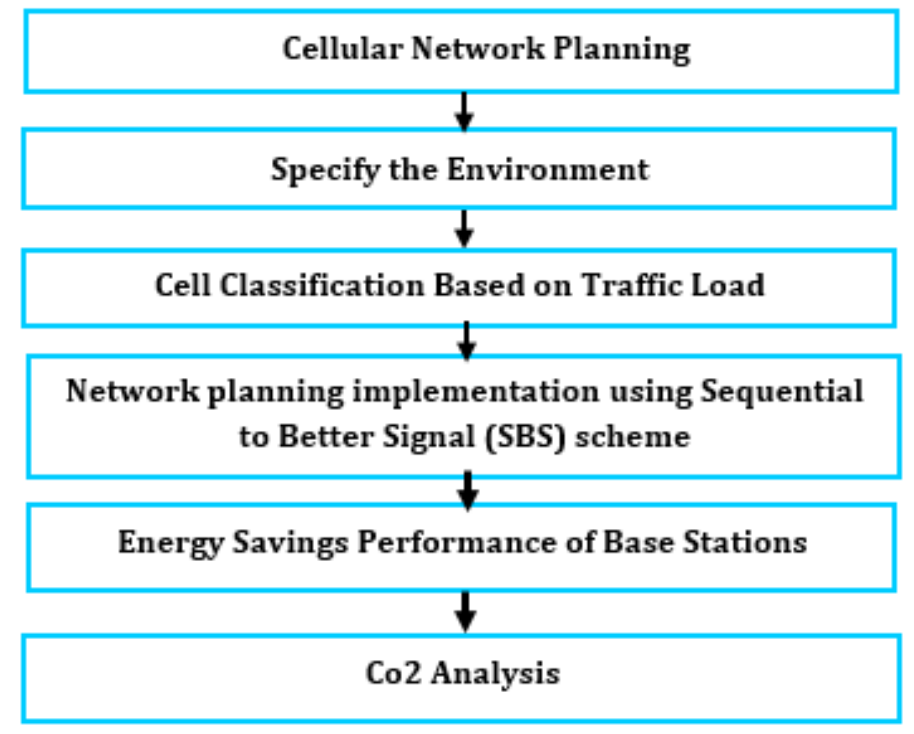

Figure 3. Diagram Block Application System

\subsection{Cellular Network Planning}

In this stage, the data being used are traffic data and site data to determine the network planning. Where site data is used to determine the location of the research object area and its coverage area, and traffic data is used to classify Base Station based on load traffic (Central cell or Neighbor Cell) as shown in Table 1. 
Table 1. Site and Traffic Data [9].

\begin{tabular}{|c|c|c|c|}
\hline BS Name & eNodeB ID & Longitude & Latitude \\
\hline Taman Bungkul & 232980 & 112.742 & -7.29122 \\
\hline Bumi Putera & 232014 & 112.739 & -7.29778 \\
\hline Kapuas & 232690 & 112.734 & -7.29844 \\
\hline Kutai & 232232 & 112.736 & -7.28861 \\
\hline Pulo Wonokromo & 232271 & 112.733 & -7.29314 \\
\hline
\end{tabular}

From Table 1 can be known that the data about name and location of the site based on longitude and latitude. Longitude is used to determine the location in the west or east of the north south line (meridian line), while latitude is used to determine the location in the south or north. Traffic data is obtained from Telkomsel [9]. The data obtained in the form of traffic data will be used as a determination of cell zooming operations that are adjusted to the traffic conditions and used as a classification of low load and high load for a period of 1 month (continue).

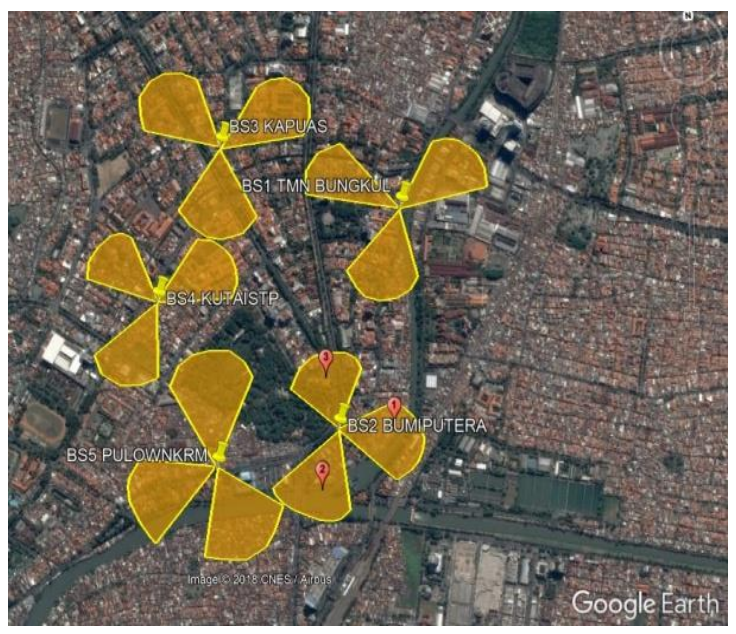

Figure 4. Object of the research area

In addition to knowing the location of the research object area, we also need to know the extent of coverage that can be reached by each BSs, as shown on Figure 4. The propagation loss calculation is one of the initial steps in planning radio links, and to take into account the propagation losses used by the propagation model in accordance with the state of the region where the network will be used. One of the methods used is the propagation model COST-231 Walfisch Ikegami because the type of environment used is urban. The COST-231 propagation model can be calculated by the equation (1) and (2) below [10]: 
$\mathrm{L}_{\mathrm{LOS}}[\mathrm{dB}]=42,6+26 \log _{10} \mathrm{~d}[\mathrm{~km}]+20 \log _{10} \mathrm{f}[\mathrm{MHz}]$

$\mathrm{L}_{\mathrm{NLOS}}[d B]=L_{p s}+L_{r t s}\left(w, f, \Delta h_{m}, a\right)+L_{\text {mod }}\left(\Delta h_{b}, h_{b}, d, f, b\right)$

where :

- $\mathrm{d}$ is the distance of BTS with MS assuming a range of values of $0.02-5 \mathrm{~km}$

- $\quad h_{b}$ is a BS antenna height assuming a range of $4-50$

$\mathrm{m}$

- $h_{m}$ is a MS antenna height assuming a range $1,5 \mathrm{~m}$

- $h_{\text {Roof }}$ is the building height assuming a range $50-200 \mathrm{~m}$

- $\phi$ is the angle between the road and direct ratio path assuming the range $0^{\circ}-90^{\circ}$

- $L_{F S}$ is a free space path loss that can be calculated using the equation (3) below:

$L_{F S}[\mathrm{~dB}]=42,6+26 \log _{10} \mathrm{~d}[\mathrm{~km}]+20 \log _{10} \mathrm{f}[\mathrm{MHz}]$

- $L_{r t s}\left(\mathrm{w}, \mathrm{f}, \Delta_{h m}, \alpha\right)$ is a roof-to-street loss that can be calculated using the equation (4):

$L_{r t s}[\mathrm{~dB}]=-8,8+10 \log _{10}(\mathrm{f}[\mathrm{MHz}])+20 \log _{10}\left(\Delta h_{m}[m]\right)-10 \log _{10}(\mathrm{w}$ $[\mathrm{m}])+L_{\text {ori }}$

$L_{\text {ori }}$ is a street orientation function whose value is:

$$
L_{\text {ori }}=\left\{\begin{array}{cc}
-10+0,35 \phi, & 0 \leq \phi \leq 35^{\circ} \\
2,5+0,075(\phi-35), & 35^{\circ} \leq \phi \leq 55^{\circ} \\
4,0+0.114(\phi-55), & 55^{\circ} \leq \phi \leq 90^{\circ}
\end{array}\right.
$$

- $L_{\text {msd }}\left(\Delta \mathrm{h}_{\mathrm{b}}, \mathrm{h}_{\mathrm{b}}, \mathrm{d}, \mathrm{f}, \mathrm{b}\right)$ is a multi-diffraction loss that can be calculated using the equation (5):

$$
\begin{aligned}
L_{m s d}[\mathrm{~dB}]= & L_{b s h}+k_{a \mathrm{a}}+k_{d} \log _{10}(\mathrm{~d}[\mathrm{~km}])+k_{f} \log _{10}(\mathrm{f}[\mathrm{MHz}]) \\
& -9 \log _{10}(\mathrm{~b})
\end{aligned}
$$

- $L_{b s h}$ is a shadowing gain (negative loss) whose value is :

$$
L_{b s h}= \begin{cases}-18 \log _{10}\left(1+\Delta h_{b}\right), & h_{b}>h_{\text {Roof }} \\ 0 \quad & h_{b} \leq h_{\text {Roof }}\end{cases}
$$

- $k_{a}, k_{d}, k_{f}$ is a constant of correction of dependence of losses on distance and frequency, with values:

$$
k_{a}=\left\{\begin{array}{lr}
54 & , \Delta h_{b}>0 \\
54+0,8+\left|\Delta h_{b}\right| & , \Delta h_{b} \leq 0 \text { dan } d_{k m} \phi \geq 0,5 \\
54+0,8+\left|\Delta h_{b}\right|\left(d_{k m} / 0,5\right) & , \Delta h_{b} \leq 0 \text { dan } d_{k m} \phi \leq 0,5
\end{array}\right.
$$




$$
\begin{aligned}
& k_{d d}=\left\{\begin{array}{cc}
18 & , \Delta h_{b}<0 \\
18+15\left(\left|\Delta h_{b}\right| / h_{\text {Roof }},\right. & \Delta h_{b} \leq 0
\end{array}\right. \\
& k_{f}=\left\{\begin{array}{cc}
0,7\left(\frac{f_{M H z}}{925}-1\right), & \text { sub-urban } \\
1,5\left(\frac{f_{M H z}}{925}-1\right) & \text { area metropolitan }
\end{array}\right.
\end{aligned}
$$

\subsection{Determine the Environment}

In telecommunications, based on ITU-R, environmental classification is divided into 2 types, namely based on user mobility and based on population density. Based on the environmental conditions in the object of research, there are many high-rise buildings for offices and the number of residential areas in the area of research objects, if viewed from the type of user mobility, then included in the category of High density-in building. If viewed from the population density, it is included in the urban category [11].

\subsection{Cell Classification}

Cell classification is one of the most important steps to operate cell zooming techniques, because with this classification we can find out which central cell and neighbor cell. Figure 5 shows the block diagram of cell classification.

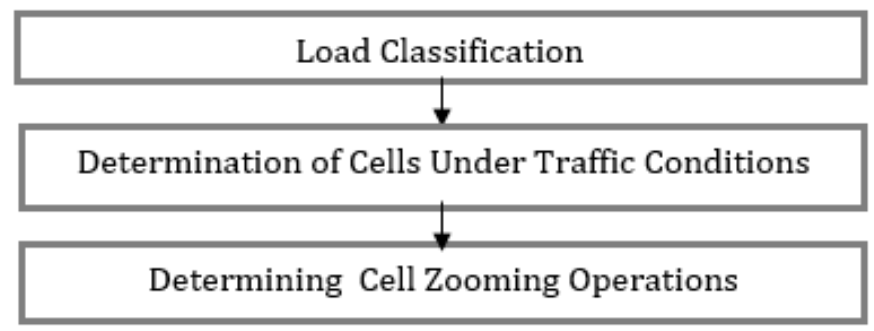

Figure 5. Block Diagram Cell Classification

There are provisions used to determine when a cell is referred to as central and neighbor. The following are the conditions: [6]

1. Central, if a cell has the highest or lowest value.

2. It says neighbor, if there are several cells with a load other than the value held by the central cell. 


\subsection{Application Cell Zooming Technique Using Sequential to Better Signal (SBS) Scheme}

The cell zooming technique implemented the SBS scheme and the algorithm processes sequentially from one BS to another based on the received SINR, i.e. $B_{i, n}=\left\{B_{i, 1}^{n}, B_{i, 2}^{n}, B_{i, N i, b}^{n}\right\}, S_{N} R_{i, p}^{n} \geq \operatorname{SINR}_{i, p}^{n}, p<q$.

Figure 6 shows the details step by step.

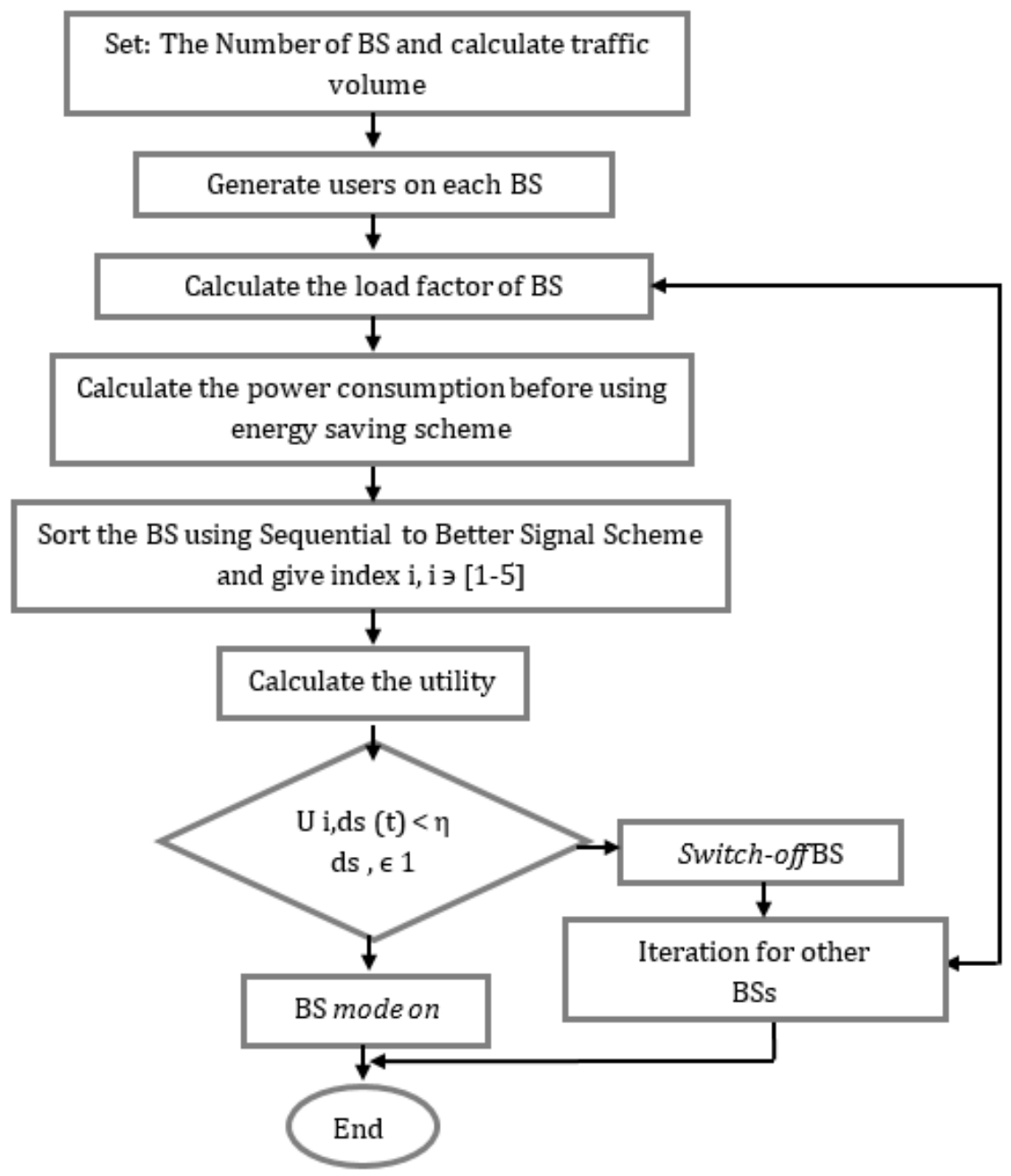

Figure 6. Centralized Algorithm Implementation

\section{A. Traffic Volume}

Calculating traffic volume is the first step that must be done in this research. Where after calculating the amount of traffic, we can find out which are cells the central cells and which are the neighboring cells. The way to calculate traffic volume is shown in equation (6): Payload $(\mathrm{MB})=\mathrm{UL}$ traffic volume + DL traffic volume 
Table 2. Payload Calculation Results

\begin{tabular}{|c|c|}
\hline BS Name & Payload (MB) \\
\hline Taman Bungkul & 1811.36 \\
\hline Bumi Putera & 4944.58 \\
\hline Kapuas & 3136.97 \\
\hline Kutai & 4789.9 \\
\hline Pulo Wonokromo & 3742.46 \\
\hline
\end{tabular}

As we know in Table 2, Base Station also being the central Base Station and the others are the neighbor BS.

\section{B. Generate User}

Generated user is the second stage that is carried out in this research, where we will know the number of users to be simulated for the application of cell zooming. Table 3 show the user mobility in several period.

Table 3. Users Mobility

\begin{tabular}{|c|c|c|c|c|c|}
\hline \multirow[b]{2}{*}{ Periode } & \multicolumn{5}{|c|}{ The Number of Mobile User Each Period } \\
\hline & $\begin{array}{c}\text { Taman } \\
\text { Bungkul }\end{array}$ & $\begin{array}{l}\text { Bumi } \\
\text { Putera }\end{array}$ & Kapuas & Kutai & $\begin{array}{c}\text { Pulo } \\
\text { Wonokromo }\end{array}$ \\
\hline $06.00-09.00$ & \multirow{2}{*}{41} & \multirow{2}{*}{15} & \multirow{2}{*}{35} & \multirow{2}{*}{49} & \multirow{2}{*}{65} \\
\hline $10.00-13.00$ & & & & & \\
\hline $10.00-13.00$ & \multirow{2}{*}{-4} & \multirow{2}{*}{-1} & \multirow{2}{*}{-25} & \multirow{2}{*}{3} & \multirow{2}{*}{-5} \\
\hline $14.00-17.00$ & & & & & \\
\hline $14.00-17.00$ & \multirow{2}{*}{-19} & \multirow{2}{*}{3} & \multirow{2}{*}{-24} & \multirow{2}{*}{4} & \multirow{2}{*}{-45} \\
\hline $18.00-21.00$ & & & & & \\
\hline $18.00-21.00$ & \multirow{2}{*}{-54} & \multirow{2}{*}{-23} & \multirow{2}{*}{0} & \multirow{2}{*}{-73} & \multirow{2}{*}{-59} \\
\hline $22.00-01.00$ & & & & & \\
\hline $22.00-01.00$ & \multirow{2}{*}{-20} & \multirow{2}{*}{-22} & \multirow{2}{*}{-49} & \multirow{2}{*}{-37} & \multirow{2}{*}{-44} \\
\hline $02.00-05.00$ & & & & & \\
\hline
\end{tabular}

\section{Load Factor}

The load factor in this research is used to determine the traffic capacity offered on the cell. The load factor value has a range between 0 to 1 , to equalize the value, then converted into a constant value to $0 / 100=0$ and $100 / 100=1$, so the load factor value has a range of values between 0 - 1 . In this research, the data obtained from the provider is the amount of resource block (RB) used and the number of resource blocks available. Thus, the load factor value in this study can be calculated by the following equation (7):

Load Factor $=\frac{\text { PRB UL Used }}{\text { PRB UL available }}$ 
Table 4. Load Factor Calculation

\begin{tabular}{|c|c|c|c|c|}
\hline Start Time & $\begin{array}{c}\text { PRB.UL. } \\
\text { Used.Avg }\end{array}$ & $\begin{array}{c}\text { PRB.UL. } \\
\text { Available }\end{array}$ & Load Factor & Average LF \\
\hline 06:00 AM & 9.641 & 75 & 0.128 & \multirow{2}{*}{0.166} \\
\hline 07:00 AM & 10.856 & 75 & 0.144 & \\
\hline 08:00 AM & 13.797 & 75 & 0.183 & \\
\hline 09:00 AM & 15.672 & 75 & 0.185 & \\
\hline
\end{tabular}

\section{Power Consumption of Macrocell Base Station}

A macrocell base station typically consists of different power consuming components. These components are shown in Figure 7 and can be divided into two groups [13].

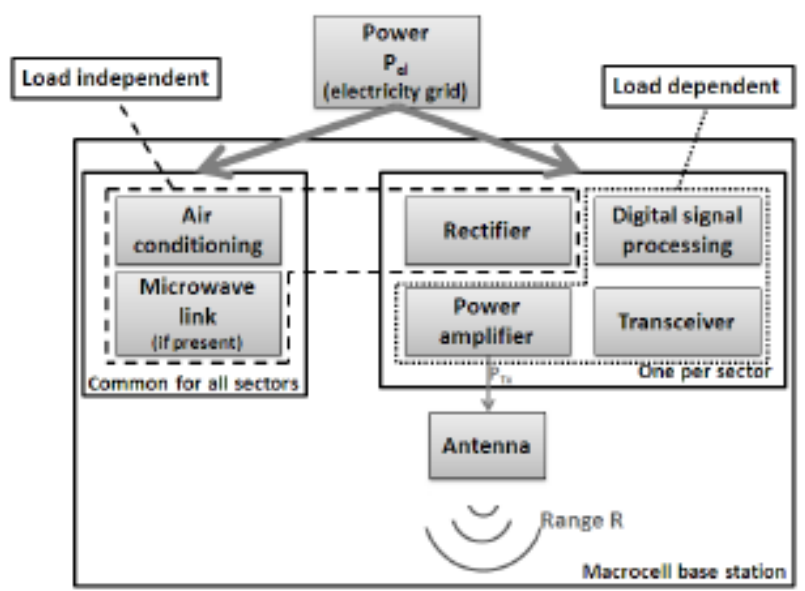

Figure 7. Macrocell BS Power Consumption

Considering the power consumption of each component, the components can also be divided in the following categories. A first category consists of the components whose power consumption is not load dependent such as the rectifier, the microwave link, and the air conditioning. The second category is the equipment that has a loaddependent power consumption (denoted as Pel/load) such as the power amplifier, the transceiver, and the digital signal processing. the power consumption of each component is known, the power consumption Pel/macro of the macrocell base station can be determined as follows equation (8) in Watt:

$p_{\text {el/macro }}=p_{\text {el/const }}+p_{\text {el/load }} \times \mathrm{Li}$

where,

$$
\begin{aligned}
& p_{\text {el/const }}=n_{\text {sector }} \times p_{\text {el/rect }}+p_{\text {el/link }}+p_{\text {el } / \text { airco }} \\
& p_{\text {el/load }}=n_{\text {sector }} \times\left(n_{T X} \times\left(p_{\text {el/amp }}+p_{\text {el/trans }}\right)+p_{\text {el } / \text { proc }}\right.
\end{aligned}
$$


Table 5 shows the typical power consumption of the different components for the technologies considered.

Table 5. BS Power Consumption Parameter

\begin{tabular}{|l|c|c|}
\hline \multicolumn{1}{|c|}{ Parameter } & Definition & Value \\
\hline$n_{\text {sector }}$ & Number of sectors & 3 \\
\hline$n_{T X}$ & $\begin{array}{c}\text { Number of transmitting } \\
\text { antennas per sector }\end{array}$ & 1 \\
\hline$p_{\text {el/proc }}$ & Digital Signal Processing & $100 \mathrm{~W}$ \\
\hline \multicolumn{1}{|c|}{$\eta$} & Power Amplifier & $12,8 \%$ \\
\hline$p_{\text {el/trans }}$ & Transceiver & $100 \mathrm{~W}$ \\
\hline$p_{\text {el/rect }}$ & Rectifier & $100 \mathrm{~W}$ \\
\hline$p_{\text {el/airco }}$ & Air Conditioning & $225 \mathrm{~W}$ \\
\hline$p_{\text {el/link }}$ & Microwave Link & $80 \mathrm{~W}$ \\
\hline
\end{tabular}

\section{E. Sequential to Better Signal (SBS) Scheme}

This SBS scheme will be used to sort neighboring BS based on the provisions of the EU association (User Equipment). By listing only BS neighbors that are active, the BS in sleep mode allows sleep for a longer time and the number of switching is reduced. Under SBS scheme, $\mathrm{Bn}$ is a neighboring $\mathrm{BS}$ set in a descending sequence from SINR (Signal to Interference plus Noise Ratio) received. To calculate the user's SINR value, equation (11) can be used below.

$\operatorname{SINR}=\frac{P r}{N_{o}+\sum_{i=\mathrm{n}}^{k} P_{i}}$

where, Pr is the user received power from eNodeB (downlink). $N_{\circ}$ is thermal noise power, and $P_{i}$ is the total sum of intracell and intercell interference. The SINR calculation flowchart is shown in Figure 8 below: 


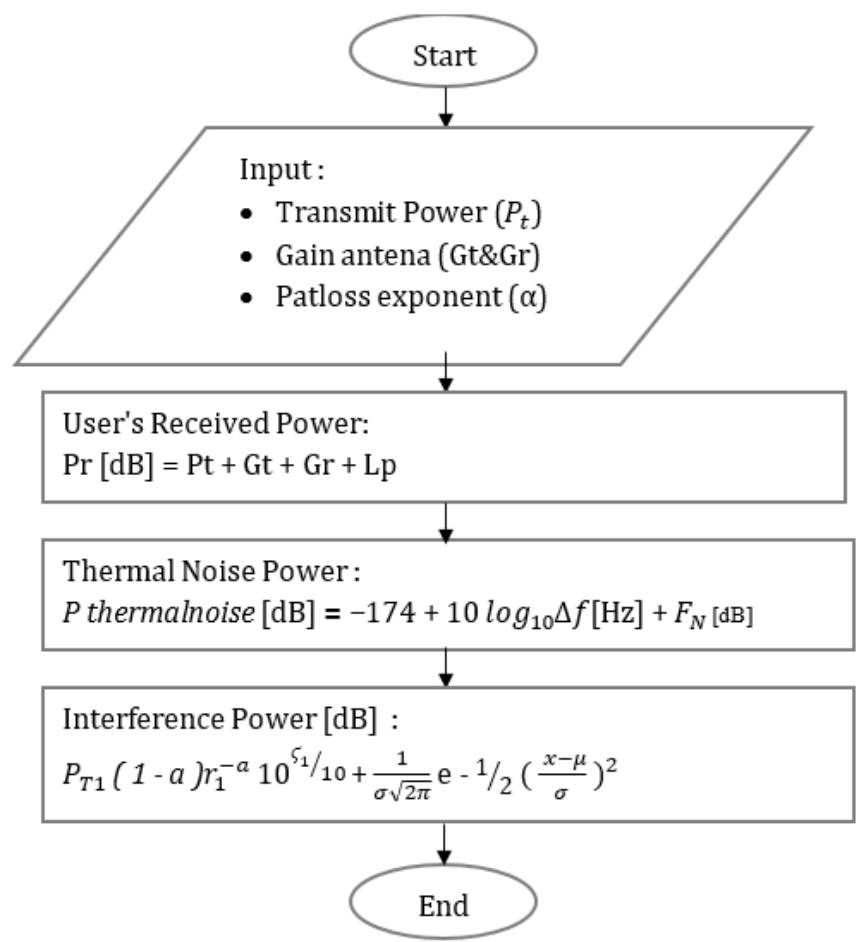

Figure 8. Block Diagram SINR Calculation

$P r$ is the received power that is used as one of the inputs to calculate SINR. Where $P t$ is the base station transmit power with a range of $42 \mathrm{dBm}$ to $46 \mathrm{dBm}$. Gt and $G_{r}$ is the gain of the transmitting antenna and the gain of the receiving antenna. The gain value based on the antenna datasheet used, in this research is $17.6 \mathrm{dBi}$ with antenna type ATR451704v01, and $L_{p}$ is pathloss (COST-231 Walfisch-Ikegami).

Thermal noise or often also called Johnson Noise is a noise phenomenon related to material temperature. The higher the component temperature, the greater the noise power. $\Delta f$ is the bandwidth used, which in this study uses $15 \mathrm{MHz}$ bandwidth. While $F_{N}$ is a noise figure (downlink) with a value of $7 \mathrm{~dB}$.

Intracellular interference is interference coming from within the BS: this interference is caused by the partial loss of the orthogonality among the users due to the multipath effect. Because the interference sources are fixed BSs in the downlink direction, to a certain mobile, the downlink interference is inevitably linked to the mobile's location. Where $a$ is the orthogonality factor of 0.7 and pathloss exponent $(\alpha)$ for the urban environment of $2.7-3.5 . r_{1}$ is the base station (random) distance for each user which is calculated by the pyhtagoras formula. Attenuation $(\xi)$ caused by shadowing can be calculated with a normal Gaussian distribution.

The calculation of inter-cell interference will also be used as one of the input parameters of the sequential to better signal scheme. 
Because switching BSs are dynamic (working based on traffic conditions), inter-cell interference can vary across networks, which is very difficult to trace. Therefore, for computational tractability, dynamic inter-cell interference can be ignored and think of it as Gausslike noise.

\section{F. Utility}

At this stage, the calculation of the Base Station utility will be carried out which will accept the mobile user as one of the parameters for applying a centralized algorithm. The utility calculation is shown in equation (12) below:

$U_{\mathrm{l}, B S}(\mathrm{t})=\sum_{\mathbb{l}=1}^{\mathrm{f}} P_{1}^{*}(\mathrm{t}) /\left\{P_{i}(\mathrm{t})+\sum_{\mathbb{l}=1}^{\mathrm{f}} P_{\mathbb{1}}(\mathrm{t})\right\}$

where $\mathrm{f}$ is the number of EU serving BSs from Bi, while $\mathrm{Pl}^{*}(\mathrm{t})$ and $\mathrm{Pl}^{*}$ $(t)$ represent the total operating power of the neighboring BS before and after the association. If the utility on the BS is worth less than the efficiency coefficient BS, Ui, BS $(t)<\eta$ BS, (where $\eta$ BS $\epsilon$ [0.1] is a constant), states that energy saving can be achieved by changing the BSi to sleep mode.

\section{G. Energy Saving of Base Stations}

It is assumed that additional baseband signal processing power consumed because of cooperation between active BSs can be neglected compared to conventional (non-cooperative) BS transmission / reception power consumption. It is defined that $\eta$ is the ratio of $P_{R F}$ to $P_{\text {total }}$ and $\lambda$ as the ratio of the total transmit power needed for cooperative transmission to the transmit power required in conventional (non-cooperative) operations to maintain the same minimum QoS level.

During energy saving operation, $\beta \times 100 \%$ BS is turned off, resulting in $\beta$ Ptotal power savings. However, the traffic load from the BS that is turned off is moved to the remaining active BS. This means that the total transmit power with the PRF, will increase with the $\lambda$ factor during energy saving operations to achieve the required QoS level, reducing the net power savings on the network. Therefore, the percentage of power saving $\xi$ during energy saving operations can be calculated as in the following equation (13) [12]:

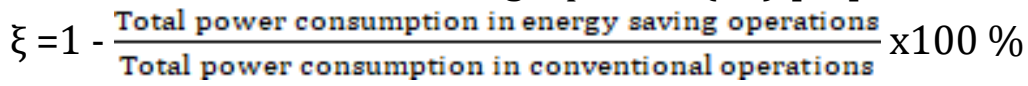

\section{H. CO2 emissions}

Global Warming is a term used to describe the increase in the average temperature of the Earth's atmosphere and the ocean gradually, a change that is believed to change the earth's climate permanently. Emissions derived from the energy we buy or bring in from outside, for example the electricity we use from PLN or steam 
from outside suppliers. It is assumed that PLN's electricity uses coal fossils fuel. The amount of carbon emissions generated from the use of electrical energy can be calculated using conversion factor Green House Gas (GHG) emissions from various energy sources as seen on Figure 9 and as follow equation (14) [13]:

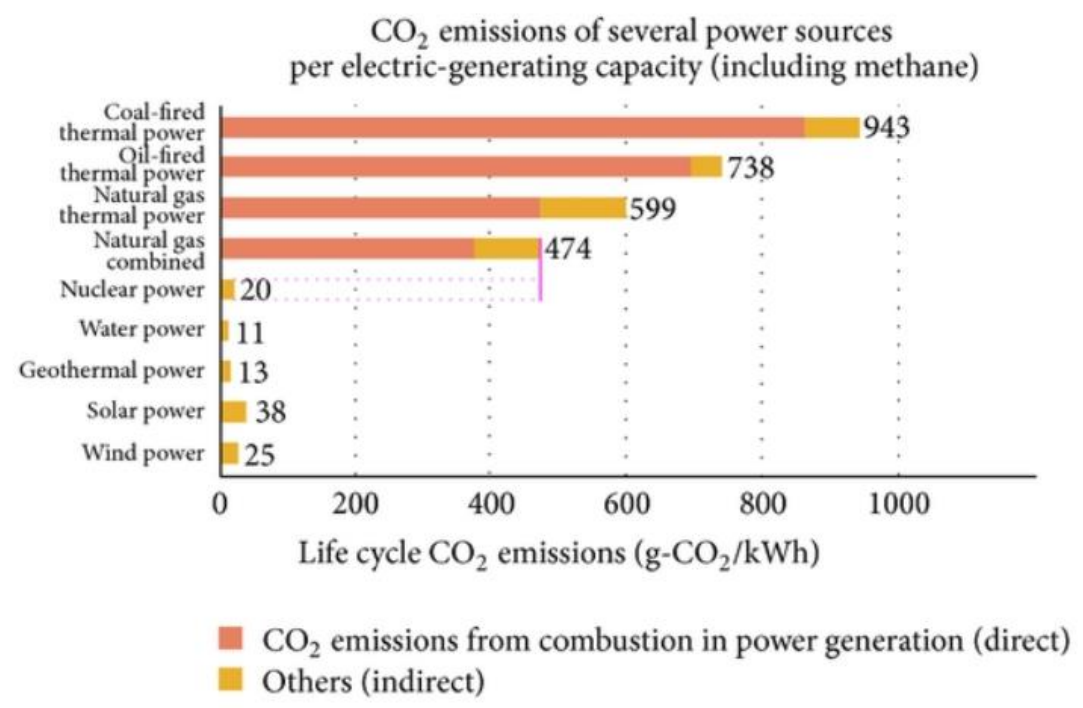

Figure 9. GHG emissions from various energy sources

$\mathrm{CO} 2(\mathrm{~kg})=$ Amount of electricity usage $(\mathrm{kWh}) \times$ conversion factor $(\mathrm{kg} / \mathrm{KWh}) / 1000$

\section{EXPERIMENT AND ANALYSIS}

This stage discusses network performance analysis on Macrocell Base Station (BS) using a centralized algorithm. Analyze based on the data used to determine the switching BS. Energy consumption before and after using the cell zooming technique, the percentage of energy savings produced, and the reduction of $\mathrm{CO} 2$ emissions that contribute to reducing global warming.

\subsection{Analysis of Base station energy consumption before and after cell zooming techniques}

The power consumption at 5 BS before and after using the cell zooming technique is different as shown in Figure 10. 


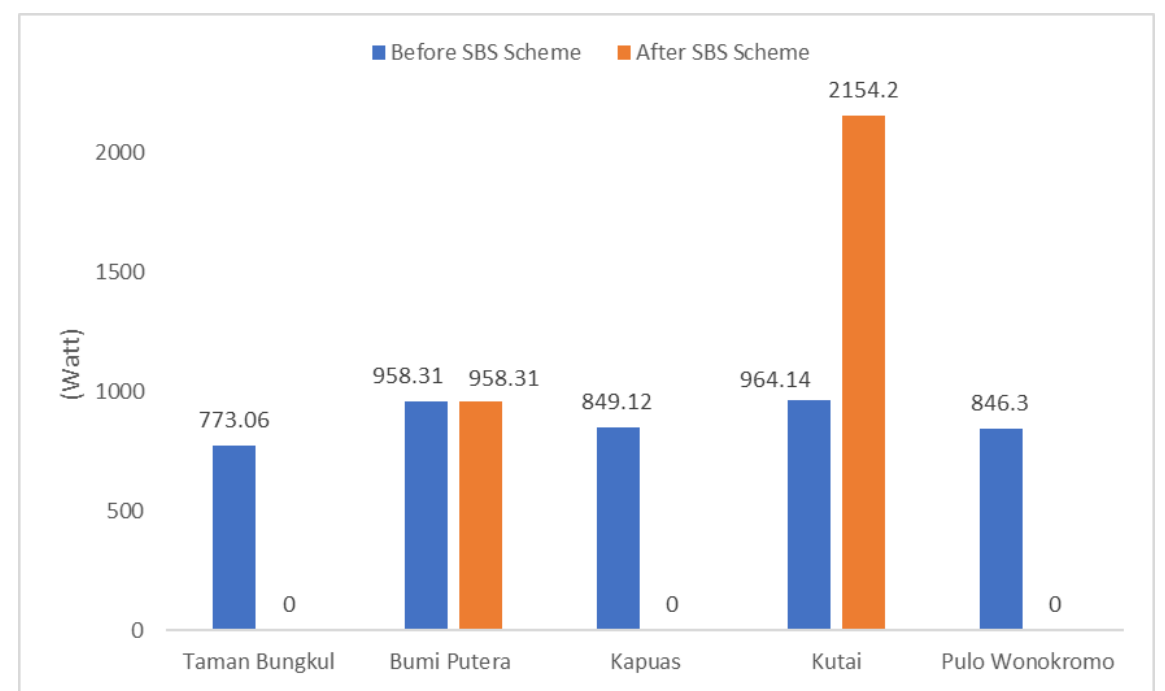

Figure 10. Energy Consumption of Each Base Stations

The power consumed by the BS before using the cell zooming technique is 4391.3 watt, these includes the power consumption of Taman Bungkul BS 773.06 watt, Bumi Putera 958.31 watt, Kapus BS is 849.12 watt, Kutai 964.14 watt, and Pulo Wonokromo 846.3 watt. The amount of energy is caused by all BSs are in switch on condition even though the traffic is low. After using cell zooming technique, the power consumed of all BSs drops into 3112.5 watts. Because there are 3 BS that switched in sleep mode: Taman Bungkul, Kapuas, and Pulo Wonokromo. So, the remaining 2 BSs are stay in mode on: Bumi Putera and Kutai BS. Here, the BS that will cover all users from the central BS is BS Kutai. so, BS Kutai must zoom out to be able to serve the users and automatically increase its power consumption. This causes after the SBS scenario the energy consumption of BS Kutai is greater than before the SBS scenario. Because BS Kutai serves users of 3 BS in sleep mode.

\subsection{Analysis of Percentage Energy Saving Base Stations}

After knowing the total energy consumed by BS as shown on Figure 10 , we can find out how much the percentage of savings is in 1 research cluster. Referring to Figure 8 and equation (13), the percentage of energy savings using the SBS scheme reaches $29.12 \%$. This result is lower than reference [8] research.

The research [8] only considers the transmit power of the BS but in the SBS scheme the signal to noise ratio (SINR) is added due to the user. The interference parameters are intracell and intercell interference. It turns out that SINR has a big influence on user receiver power, so there are some BSs according to research [8] can be sleep mode but because the SINR value is lacking, the BS must be active. 


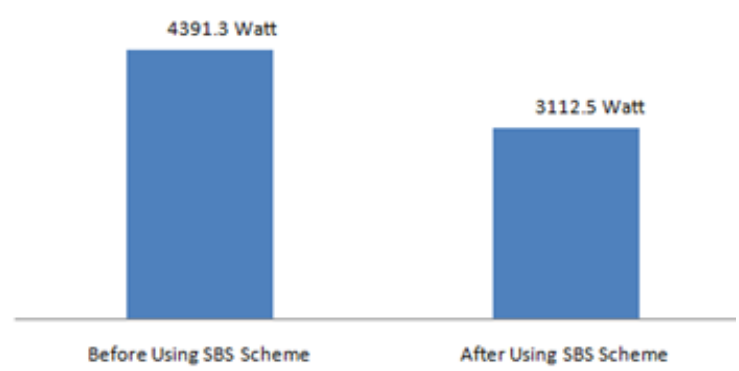

Figure 10. Total Power Consumption of BSs

The result that has been taken before utilizing SBS scheme produce $4.4 \mathrm{~kW}$ for 3 hours or it is equivalent with $12848 \mathrm{kWh} /$ year while SBS can produce $3.1 \mathrm{~kW}$ for 3 hours or it is equivalent with 9052 $\mathrm{kWh} /$ year. However, the use of energy consumption is still below energy consumption for UMTS technology which is $26268 \mathrm{kWh} /$ year [14].

\subsection{Analysis of CO2 Reduction}

The use of electricity in base station activities can contribute to greenhouse gas emissions, especially C02. In this study, CO2 emission reduction was measured through the management of electricity use with the sleep mode of BS method. In general, the pattern of electricity usage for BS operations is turned on in the morning and turned off during rest / sleep hours. Thus, the use of electrical energy will decrease a lot at night and this condition can be used to apply cell zooming techniques.

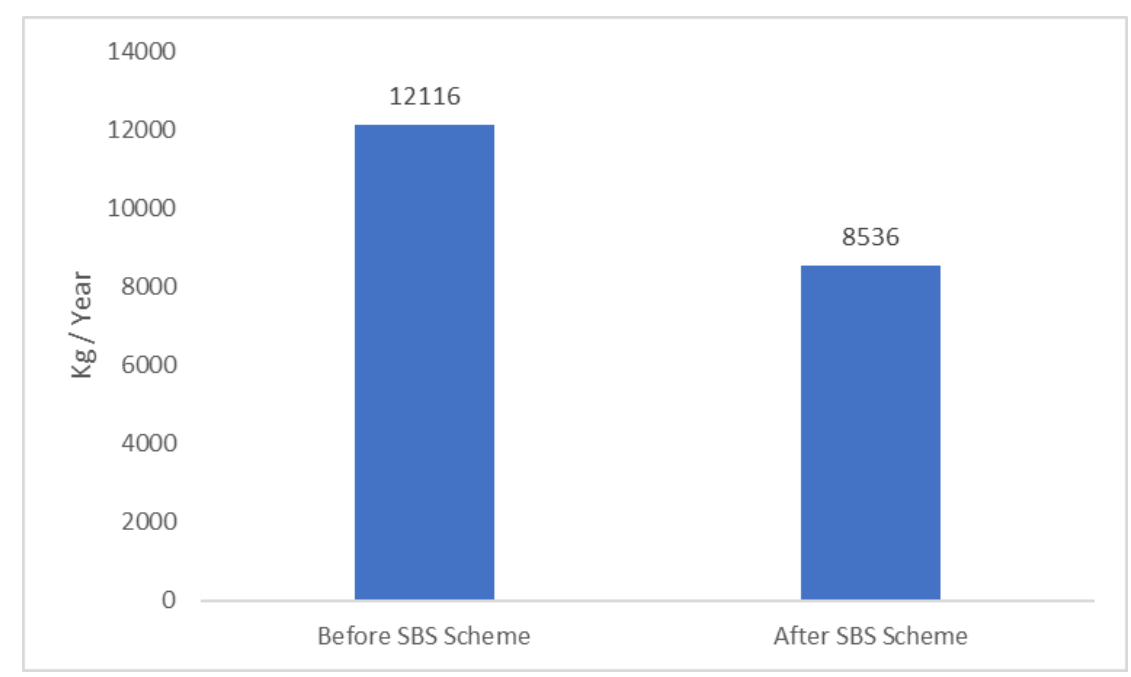

Figure 11. $\mathrm{CO} 2$ reduction 
Figure 11 shows the reduction of $\mathrm{CO} 2 /$ year. Before using cell zooming technique, $\mathrm{CO} 2$ emissions in the air that produced by all BSs are $12116 \mathrm{~kg} /$ year and after using the cell zooming technique the emission is reduced to $8536 \mathrm{~kg} /$ year that is around $3580 \mathrm{~kg} /$ year.

\section{CONCLUSION}

The high and low value of the power consumed by the base station depends on the load factor and the high and low load factor values are influenced by the number of users. So that the three are interrelated and influence. Before using cell zooming technique, the highest power consumption is owned by Kutai base station, which is 964.14 Watt. While the lowest is owned by BS Taman Bungkul with a value of 773.06 Watts. From the results of the technique of applying cell zooming techniques with the SBS (Sequential to Better Signal) scheme, the percentage of energy savings produced ranges from 29,12\%. And the last is CO2 emissions all BSs are $12116 \mathrm{~kg} /$ year and after using the cell zooming technique the emission is reduced to $8536 \mathrm{~kg} /$ year that is around $3580 \mathrm{~kg} /$ year.

\section{ACKNOWLEDGEMENTS}

In arranging this research, a lot of people have provided motivation, advice, and support for the researcher. I am enormously grateful to my collage Mr. Ahmad Hafidz for continuous encouragement, good advice and assistance to provide the data needed.

\section{REFERENCES}

[1] D. Margot, T. Emmeric, J. Wout, et al. , Modelling and optimization of power consumption in wireless access networks, Computer Communication, vol. 34, pp. 2036-2046, Apr. 2011.

[2] B. Rengarajan, G. Rizzo, and M.A. Marsan, Bounds on QoS-constrained energy savings in cellular access networks with sleep modes, in Proc. International Teletraffic Congress (ITC), 2011, pp. 47-54.

[3] J. T Louhi, Energ Efficiency of modern cellular base stations, 29th International Telecommunications Energy Conference (INTELEC), 2007, pp.475-476, Sept 30 2007-oct. 42007.

[4] H. Karl, An overview of energy-efficiency techniques for mobile communication systems, Technical Report, Telecommunication networks Group, Technical University Berlin, Sept. 2003.

[5] Tun Cho Khin, Kunavut Kunagor, An Overview of Cell Zooming Algorithms and Power Saving Capabilities in Wireless Networks , KMUTNB Int J Appl Sci Technol, Vol.7, No.3, pp. 1-13, 2014.

[6] Zhiseng Niu, Zexi Tsinghua, Yiqun Wu, Jie Gong, Cell Zooming for CostEfficient Green Cellular Networks, IEEE Communication Magazine, 2010 . 
[7] Md. Farhad Hossain, Traffic-Driven Energy Efficient Operational Mechanisms in Cellular Access Networks, Thesis, University of Sidney, 2014.

[8] Hani'ah M, Rosabella I. Y., Okkie P, Nur Adi , Ari W Performance Analysis of Cell Zooming Based Centralized Algorithm for Energy Efficient in Surabaya, EMITTER International Journal of Engineering Technology, Vol. 4, No. 2, 2016.

[9] Courtesy of Telkomsel Data 2018.

[10] Path loss models. S-72.333 Physical layer methods in wireless communication systems, Helsinki University of Technology, Nov. 2004.

[11] ITU R-Recommendation M.1390, Methodology for the calculation of IMT-2000 terrestrial spectrum requirements, International Telecommunication Union, 1999.

[12] M. Deruyck, W. Joseph, L. Martens, Power Consumption Model for Macrocell and Microcell Base Stations, Eur. Trans. Telecomms., pp. 114, Jun. 2011.

[13] Lamiaa Abdallah, Tarek El-Shennawy, Reducing Carbon Dioxide Emissions from Electricity Sector Using Smart Electric Grid Applications, Journal of Engineering Hindawi , Volume 2013, Article ID 84505, https://doi.org/10.1155/2013/845051

[14] Carmine Lubritto Telecommunication Power System: Energy Saving, Renewable Sources and Environmental Monitoring, Trends in Telecommunications Technologies, ISBN 978-953-307-072-8 pp146164, 01, March, 2010. 